\title{
The Role of Gamification in Health Behavior Change: A Review of Theory- driven Studies
}

\author{
Manuel Schmidt-Kraepelin \\ Karlsruhe Institute of \\ Technology \\ $\underline{\text { manuel.schmidt-kraepelin@kit.edu }}$
}

\author{
Simon Warsinsky \\ Karlsruhe Institute of \\ Technology \\ uzdpu@student.kit.edu
}

\author{
Scott Thiebes \\ Karlsruhe Institute of \\ Technology \\ scott.thiebes@kit.edu
}

\author{
Ali Sunyaev \\ Karlsruhe Institute of \\ Technology \\ sunyaev@kit.edu
}

\begin{abstract}
Gamification is increasingly being recognized as a tool to support a change in individuals' health behaviors. However, how and under which circumstances gamification is able to support health behavior change is still largely unexplored. This study follows the call for more theory-driven research on gamification by investigating the role of gamification in health behavior change theories (HBCTs). In order to do so, we conducted a systematic review of extant literature and identified 25 studies that explore the role of gamification in the process of health behavior change to some extent. We found large discrepancies in how the authors of these studies conceptualized the role of gamification in their theory-driven health interventions. To further strengthen theory-driven research on gamification in health and well-being, we additionally propose concrete research questions. These may guide future researchers to identify valuable avenues for further explaining and predicting the influences of gamification on health behavior change.
\end{abstract}

\section{Introduction}

Gamification is a recent trend in research and practice that aims to utilize people's inherent passion for games to evoke motivation or engagement by applying game design elements in non-game contexts. Especially in health and well-being, gamification is increasingly recognized as a valuable tool to foster the sustained usage of a system or to promote certain health behaviors [47] (e.g., through mobile health applications). Typical examples include systems that aim to promote physical activity, smoking cessation, or healthy eating habits [45].

Overall, the major goal of applying gamification in the context of health and well-being is to support users in making lasting positive changes to certain health behaviors through higher levels of motivation [51]. In fact, research has shown promising results indicating that gamification has the potential to positively influence a wide variety of different health-related effect measures, such as physical activity [21, 44].

Health behavior change is a process that is complex and difficult to achieve [10]. When confronted with a health threat, people are usually exposed to an overload of information from diverse sources such as the own body, medical professionals, family and friends, and even reports in the media. In order to gain deeper knowledge on which aspects shape the process of health behavior change, extant research has produced a variety of different health behavior change theories (HBCTs) that help researchers and practitioners to understand and predict health behavior change from different viewpoints [37]. However, it is unclear to what extent gamification researchers have based their investigations on these theories. Past reviews have either investigated the theoretical foundations of gamification without a specific context (e.g., Seaborn and Fels [49]) or focused their investigation on psychological and behavioral effects of gamification in health and well-being without explicitly elaborating on theory-based explanations of such effects [21,44]. We currently lack knowledge on the role that gamification might play when it comes to understanding and predicting when and how health behavior change arises and persists. Thus, we ask the following research question within this study: How does extant research conceive the role of gamification in health behavior change?

To answer our research question, we conduct a structured review of literature. In particular, we review those publications that draw on HBCTs as theoretical lenses to discuss and elaborate on the role of gamification for health behavior change. Our content analysis enables us to identify how gamification has been conceptualized and utilized by these studies in the context of HBCTs. In addition, based on our results, we derive a research agenda that highlights potential avenues for future research in the intersection of 
gamification and health behavior change. By doing so, we lay the foundation for more theory-driven research that helps to shed light on the role of gamification in eliciting and sustaining health behavior change. In particular, our research contributes to answering the frequently expressed call for more theory-driven research that helps to explain the effects of gamification.

The remainder of this paper is structured as follows: In section two, we give a brief introduction to extant research on behavior change through gamification and the most common HBCTs. We then give an overview of our research approach in section three. Section four highlights the main results of our review. In section five, we discuss the results of our derived avenues for future research, and elaborate on potential limitations of our study. We end with a brief conclusion in section six.

\section{Theoretical Background}

\subsection{Behavior Change through Gamification}

The concept of gamification has started to gain widespread attention by information systems (IS) researchers and practitioners in 2009 [53]. Literature provides two prevailing definitions for gamification. Huotari and Hamari [20] refer to gamification as the process of enhancing services with motivational affordances for gameful experiences. Deterding et al. [7] define gamification as "the use of game design elements in non-game contexts". Popular game elements used in gamification include points, badges, leaderboards, and challenges [7]. Overall, gamification aims at supporting and motivating users towards the behavior that the gamified system is targeting.

The first wave of gamification research focused on answering the blanket question, whether gamification works or not [38]. In order to do so, researchers tested a wide variety of different gamified systems, including combinations of all kinds of game design elements. While these studies certainly helped to establish gamification as a scientific research stream, researchers increasingly call for theory-driven studies that aim to tease out the effects, moderators and mediators of individual game design elements [38]. First studies exist that aim to tackle this issue by identifying suitable theoretical lenses for investigating the motivational effects of gamification. For example, Seaborn and Fels [38] reviewed twelve papers that proposed an explanation of the underlying nature of gamification based on already existing theories from other domains. The results of their study suggest that the most commonly used theoretical lens for gamification research is the self-determination theory (SDT) [43]. Furthermore, Putz and Treiblmaier [40] developed a theory-based research agenda for eleven different wellknown theoretical lenses such as flow theory and information processing theory. Finally, Liu et al. [34] elaborate on different theoretical perspectives for gamification research and propose theoretically derived design principles and a selection of resulting open research questions. However, although many gamification researchers have cautioned the vital role of context while designing gamification concepts $[17,38]$, these existing reviews do not elaborate on the value of different theoretical lenses when investigating specific contexts such as health behavior change.

\subsection{Health Behavior Change}

According to Gochman [15], health behavior includes those personal attributes, personality characteristics, behavioral patterns, actions and habits that relate to health maintenance, health restoration, and health improvement. Health behavior change is a complex and difficult to achieve process [5], potentially influenced by various different factors such as emotion, social influences or knowledge about a health condition [36]. Because of this, several theories have been applied to create meaningful health interventions and foster a deeper understanding of health behavior change. These health behavior change theories (HBCTs) are commonly used or originate from the field of healthcare. In accordance with existing research on theoretical considerations of gamification [49], we refer to an HBCT as a possibly appropriate, already existing explanatory model that has proven to provide valuable knowledge in order to explain and predict health behavior change.

Whereas there are reoccurring factors or constructs employed by several HBCTs [36], existing HBCTs differ in the way they explain and predict health behavior change. For instance, the health belief model (HBM) explains health behavior change as the result of a rational appraisal between the perceived threat of a health problem and the perceived effectiveness of countermeasures [50]. In contrast, social cognitive theory (SCT) assumes that people learn by observing others and then imitate that behavior under certain circumstances [3]. A review by Munro et al. [37] provides a comprehensive list of the most well-known HBCTs and discusses their suitability in the specific context of long-term medication adherence. Within this review, we used this list as a basis of relevant HBCTs. 


\section{Methodology}

\subsection{Data Collection}

We conducted a systematic online database search following the guidelines by Levy and Ellis [31]. The scientific databases included were PubMed, EBSCOHost, ProQuest, AiSel, ScienceDirect, IEEE $X$ plore and Scopus and the search string used was: TITLE-ABSTR-KEY (gamif*) AND TITLE-ABSTR-KEY (health OR medic* OR exer* OR life* OR wellness) AND TITLE-ABSTR-KEY (behaviour OR behavior). The search string was adapted towards the search logic of each database, while preserving the terminology.

All databases were searched on January $8^{\text {th }}, 2019$. The database search yielded a total of 561 publications. We decided to include empirical as well as conceptual studies, as the main focus of the study is the role of gamification in HCBTs, rather than the expressiveness of empirical results. We assessed the relevance of each article by utilizing predefined exclude criteria. In a first step, we excluded publications that were duplicates, not peer-reviewed, not written in English, or published before 2009. Furthermore, we excluded 89 publications that were not placed in the context of health or wellbeing, 59 publications that did not focus on gamification (The differentiation between gamification and related concepts, such as serious games, was done according to the distinction made by Deterding et al. [7]), and 30 publications that did not investigate health behavior change. Furthermore, 45 publications did not include any theoretical frame at all, whereas another 25 did not include HBCTs reviewed by Munro et al [37], but other theories like the aforementioned SDT (11 studies), or the Fogg Behavior Model (5 studies). Our approach led to a set of 18 publications. To widen the scope of our review, we conducted a forward, and a backward search. By applying the same exclusion criteria to the references of our initial set of 18 publications, we were able to identify another seven relevant publications, yielding a final set of 25 publications for analysis. Appendix A gives an overview of the identified studies.

\subsection{Data Analysis}

We conducted a manual concept-centric data analysis approach that was informed by Webster \& Watson [55]. During the coding process, the data was broken down into discrete parts (i.e., text passages), closely examined, compared for similarities and differences, and coded with regard to the phenomena as reflected in the data. We were particularly interested in how the studies conceived the role of gamification in the health behavior change process through theoretical lenses. This involved identifying individual theories, as well as determining their level of integration into an intervention. To determine the level of integration of a theory, the most important aspect to consider was the amount of information drawn from a theory in order to support the desired health behavior change. In accordance with this thought, we developed a hierarchy consisting of four classes, where a higher class implies a higher level of integration: (1) Mention (HBCT is merely mentioned, but it is not clear to which extent it informed the intervention), (2) Subsumption (HBCT is used to explain results of the intervention), (3) Partial Basis (certain parts of the intervention are informed by an HBCT), and (4) Full Basis (intervention is fully informed by HBCT).

\section{Results}

\subsection{Identified Theories}

We identified six different HBCTs that were also featured by Munro et al. [37] (see Table 1). These six HBCTs include the health belief model (HBM), the information, motivation, and behavioral skills model (IMB), the self-regulation theory (SRT), the social cognitive theory (SCT), the theory of planned behavior (TPB), and the transtheoretical model (TTM).

Table 1. Identified HBCTs

\begin{tabular}{|l|l|}
\hline HBCT & Studies \\
\hline HBM & {$[10,13,14,18,33,52]$} \\
\hline IMB & {$[28]$} \\
\hline SRT & {$[5,13]$} \\
\hline SCT & {$[6,8,9,19,22-24,32,33,48,56]$} \\
\hline TPB & {$[6,13,14,16,33,48]$} \\
\hline TTM & {$[1,18,21,23,29,33,41,42,48,54]$} \\
\hline
\end{tabular}

\subsection{Types of Studies}

The methodological approaches used in the studies were distributed relatively even. Overall, nine studies were conceptual, eight studies utilized quantitative methods, six studies utilized qualitative methods, and two studies utilized a mixed methods approach. Sample sizes ranged from $n=15$ [42] to $n=1500$ [1]. The most commonly used method was that of a randomized control trial (RCT), being employed by six studies. 


\subsection{Targeted Behaviors}

Table 2 shows the health behaviors targeted by the studies. All studies that targeted no specific health behavior were of conceptual nature, thus conducted no concrete intervention. Table 2 indicates that the majority of studies aimed to increase physical activity as the primary behavioral outcome. In his study, Cugelman [5] emphasized the importance of gamification being able to help sustain long-term behavior change in order for it to be considered effective.

Table 2. Targeted health behaviors

\begin{tabular}{|l|l|}
\hline Health behavior & Studies \\
\hline No specific behavior & {$[5,18,21,54]$} \\
\hline Physical activity & $\begin{array}{l}{[1,6,8,14,16,24,} \\
29,33,41,42,52]\end{array}$ \\
\hline Smoking cessation & {$[9,10]$} \\
\hline Chronic condition self-management & {$[13,23]$} \\
\hline Adherence to HIV therapy & {$[19,28]$} \\
\hline Healthy food consumption & {$[22]$} \\
\hline $\begin{array}{l}\text { Substance Abuse and Relationship } \\
\text { violence }\end{array}$ & {$[48]$} \\
\hline $\begin{array}{l}\text { Compliance with exercise and diet } \\
\text { prescriptions }\end{array}$ & {$[32]$} \\
\hline Support for Breastfeeding & {$[56]$} \\
\hline
\end{tabular}

\subsection{Target Groups}

The target groups of featured interventions varied. Most studies targeted a specific age group, such as adults [6, 8, 42, 56]. Only two studies targeted elderly people $[52,54]$. Three studies targeting young men [1, $29,41]$ utilized the annual military call-ups in Finland to recruit their participants. In some cases the target group was predetermined by the associated health behavior change, for example, in smoking cessation [9, 10], or chronic disease management $[13,23]$. Other studies did took a more practical approach by recruiting people interested in the intervention, e.g., through existing networks [56] or through paper flyers [6, 42].

\subsection{The Role of Gamification in Health Behavior Change Theories}

We found the role of gamification in HBCTs in our reviewed studies to vary. While some studies firmly integrated gamification elements with HBCTs (e.g., [22, $28,56])$, others saw the two as completely separate units. Those studies that drew no direct connection between gamification and HBCTs used the HBCTs either as anecdotes (e.g., $[9,18,21])$ or as explanations for the findings they made (e.g., [10, 42, 52]).The review by Lister et al. [33] investigated the occurrence of behavioral constructs from various HBCTs along with gamification elements in mobile health applications. The studies by Giunti et al. [13, 14] deconstructed the design concepts of their gamified interventions until they were in accordance with four different theories, including the HBM and TPB. The remaining studies primarily focused on utilizing single HBCTs in gamified interventions. The following sections briefly describe each identified HBCT along with our findings.

4.5.1 Health belief model (6 studies). The HBM's main assumption is that health behavior is the result of a rational appraisal of the perceived threat of a health problem against the perceived effectiveness of countermeasures [50]. In our review we found five studies that utilized the HBM. However, no study explicitly used the HBM to inform the design of a concrete intervention. Two studies $[10,52]$ drew on the HBM to explain the effects of conducted gamified interventions. In the case of Takahashi et al. [52], the effects were explicitly said to not being connected to the implemented gamification elements. El-Hilly et al. [10] found their gamified intervention to influence behavioral change by increasing perceived threat of the negative health behavior and increasing the perceived benefit of the positive health behavior. However, they did not undertake the attempt to tease out the direct influence of gamification elements.

4.5.2. Information, motivation, and behavioral skills model (1 study). According to the IMB, behavior change is influenced by the occurrence of three main elements: information, motivation, and behavioral skills [12]. Only the study by LeGrand et al. [28] used the IMB to design a gamified intervention. The authors used a multitude of gamification elements and hypothesized that these may enhance motivation for behavior change. However, the paper does not provide any empirical evidence for their hypotheses.

4.5.3. Self-regulation theory ( 2 studies). The SRT is based on the assumption that people are active, selfregulating problem solvers that are motivated to avoid and treat illness threats [30]. According to SRT, people first build cognitive representations of health threats and subsequently develop and execute plans for coping with the health problem as well as the resulting emotional distress. They then evaluate these plans, and form new cognitive representations within a feedback loop $[4,30]$. Cugelman [5] argues that the persuasive architecture of 
gamification and SRT are quite similar. From this, he concludes that interventions based on SRT should be easier to gamify. However, we did not identify any study explicitly investigating the effects of gamification on SRT-related constructs in our reviewed studies.

4.5.4. Social cognitive theory (11 studies). According to SCT, people learn and adapt behaviors by observing others. The core concept of SCT is that of reciprocal determinism, meaning that behavior is something that influences and is influenced by personal factors and the social environment [3]. SCT was the most frequently occurring theory in our review. Three studies focused on using gamification elements to influence the social environment of study participants. Jones et al. [22] did so primarily by using gamified role-model heroes to increase fruit and vegetable consumption in schools. When comparing the results to a baseline phase without gamification, they found fruit and vegetable consumption to be significantly higher in the gamification phase. Edney et al. [8] focused on using gamification elements to mimic real-life social interactions. They noted that the social and gamification features of their intervention were inherently linked with each other and that they were designed to capitalize on social comparison, support, and influence. Lin et al. [32] propose a social gaming portal which aimed at leveraging peer influence to achieve a behavior change in accordance with SCT. They argue that people play games due to the need for self-esteem and consequently used social connectivity to elicit self-esteem.

Furthermore, gamification was used in other SCTinformed interventions to influence self-efficacy. For example, Dadaczynski et al. [6] found that the implemented gamification elements points and achievements had positive effects on self-efficacy, as well as engagement and motivation. White et al. [56] focused on two constructs from SCT, observational learning and goal setting, while implementing gamification elements in the form of points, badges, and leaderboards in their intervention. Preliminary results of their study indicated a positive influence of the overall intervention, without specifically teasing out the effects of gamification elements. Lastly, Hightow et al. [19] addressed multiple key principles of SCT in their intervention. However, only the principle of reinforcement was addressed by gamification elements, specifically by virtual rewards and achievements.

4.5.5. Theory of planned behavior (6 studies). The main assumption of the TPB is that behaviors are under volitional control. According to the TPB, an individual's behavior is shaped by the attitude towards the behavior, subjective norms, and perceived behavioral control [2]. The study by Dadaczynski et al. [6] based their intervention partially on the TPB, while not explicitly linking it with gamification elements. Furthermore, Hamari \& Koivisto [16] based their research model on the TPB, specifically by extending the element of subjective norms with social influences. They found that social influences overall have a positive impact on gamified exercise interventions.

4.5.6. Transtheoretical model (10 studies). The TTM conceptualizes health behavior change as a series of stages ((1) precontemplation, (2) contemplation, (3) preparation, (4) action, and (5) maintenance), rather than a singular, discrete event [39]. Progressing through stages represents a temporal dimension, and relapsing to an earlier stage is possible. Reynolds et al. [42] argue that an individual's current stage in the TTM affects how interventions should be designed. They conclude that the same gamification elements can have different effects on individuals in different TTM stages. For example, the gamification element of points was perceived positively by individuals in an early TTM stage, whereas it was perceived negatively by individuals in later stages. However, in the case of leaderboards, the perceptions were found to be vice versa. Three studies $[1,29,41]$ based their interventions on the TTM by delivering automated tailored health messages referring to an individual's associated TTM stage. In all three studies, a gamified online service was used to deliver these messages. However, contradicting the findings of Reynolds et al. [42], the same gamification elements were used for individuals in different stages. Within these studies gamification was implemented with the aim to increase user engagement and participation [1] or compliance with the study [29].

\section{Discussion}

\subsection{Principal Findings}

In this work, we aimed to answer the question, how extant research conceives the role of gamification in health behavior change. We conducted a literature review of studies which drew upon HBCTs as theoretical lenses to elaborate on the role of gamification. Analyzing the targeted health behaviors revealed that physical activity was the most frequently targeted behavior. Sedentary lifestyles are one of the most important risk factors in modern societies with regard to premature deaths. This makes physical 
inactivity a highly relevant problem to tackle. Due to mobile health technologies, actual health behavior regarding physical activity is easier to measure and less susceptible to cheating than other behaviors that are selfreported such as healthy eating habits. Another interesting observation was that gamification elements were exclusively used to reinforce positive behaviors. For example, in studies targeting smoking cessation [9, 10], refraining from smoking was encouraged via gamification, whereas individuals were not punished by the gamification concept in case they smoked. This finding is in line with the concept of operant conditioning, which implies that positive reinforcement yields higher potential than punishment when inducing a desired behavior [35].

The most prominent target group of interventions were young people. This is not surprising, since extant research has shown that younger people have an easier time to adapt gamification technologies [25]. The reviewed studies integrated HBCTs within their interventions on different levels. Seven studies only mentioned HBCTs without any further information drawn from them and only five out of 25 studies fully relied on HBCTs to build their gamified interventions. This finding shows the absence of strong theory-driven research on gamification in health and well-being.

In regards to individual theories, we found it surprising that the TPB was outnumbered by other theories. The TPB as well as its predecessor (i.e., the theory of reasoned action) and its successor (i.e., the technology acceptance model) are widely used in IS research. Apparently, the popularity of the TPB does not carry over into gamified health interventions, possibly due to the healthcare research community favoring other, more health-specific theories.

\subsection{Future Research Avenues}

Extant research has repeatedly called for more theory-driven studies that aim to tease out the effects, moderators and mediators of individual game design elements with regard to behavior change [38]. However, our review suggests that most theory-driven studies in the context of health and well-being still focus on the overall effects of gamification on traditional outcomes, such as increased engagement, motivation, or participation. We argue that to deeper understand the role of gamification in the process of health behavior change, researchers should go beyond this understanding and undertake approaches to integrate gamification with HBCTs more profoundly. Against this backdrop, we analyzed our results and derived several possible avenues for future research. In comparison to other reviews of gamification [21, 26, 49], our propositions stand out for two reasons. First, they are specific to health behavior change. Second, we provide more concrete ideas and starting points for a deeper investigating the role of gamification as well as potential moderators and mediators of behavior change.

The study by El-Hilly et al. [10] suggests that gamified intervention have the potential to influence both major constructs of the HBM (i.e., perceived threat and perceived benefit). However, it is unclear which gamification elements are most suitable to positively influence either of those constructs. When targeting health behavior change through the lens of HBM, it would be beneficial for practitioners to understand how gamification has to be designed in order to address perceived effectiveness or perceived threat respectively. This would also provide answers on the important question, whether gamification is more applicable for either of the two. Consequently, we propose the following question: How should gamification be designed to positively affect health behavior change through perceived effectiveness and perceived threat?

According to social comparison theory [11], humans have a natural drive to evaluate themselves by comparing to others by the means of objective standards. The theory suggests that comparing oneself with others can have positive effects, for example, in the form of increased inspiration. However, research has also shown negative effects of social comparison such as envy [27]. Many gamification features, such as leaderboards, inherently promote social comparison. Thus, further studies with regard to the positive and negative effects of social comparison yielded by gamification elements need to be conducted [46]. We formulate the following research question: How does gamification elicit social comparison and what are its positive and negative influences on health behavior change?

The study by Reynolds et al. [42] suggests that the same gamification elements can have very different effects on individuals in different stages of the TTM. Thus, it would be an interesting avenue for future research to develop knowledge on how gamification should be designed and utilized for different stages of health behavior change. This may also include developing a deeper understanding of which negative consequences may occur when gamification is applied in unsuitable stages. We propose the following research question: How should gamification be designed in order to support positive health behavior change with respect to different stages of health behavior change?

The IMB builds on the assumption that information is the key construct for health behavior change. The 
value of information heavily depends on whether the recipient engages with it or not. Thus, it is a valuable avenue for future research to explore how gamification could foster health behavior change through increased engagement with delivered information. We derive the following research question: How can gamification positively affect health behavior change through higher engagement with information?

As argued by Lister et al. [33], health behavior change is unlikely to be sustained without high levels of self-efficacy. Several studies undertook first steps to identify relations between self-efficacy and gamification [5, 33]. The TPB builds on self-efficacy in the concept of perceived behavioral control, which refers to an individual's perceived ease or difficulty to perform a health behavior [2]. We did not find any study that investigated the impact of these relations on health behavior change. Thus, we argue that future research could aim to develop a deeper understanding of how gamification may lead to higher levels of self-efficacy and perceived behavioral control. We state the following question: How can gamification positively affect health behavior change through increased self-efficacy and perceived behavioral control?

\subsection{Implications}

Our study yields some implications for theory and practice. First, several studies using similar gamification elements reported different effects. This result further strengthens the theoretical assumption that gamification is highly context-sensitive. Furthermore, our results highlight that the context-sensitivity of gamification not only refers to different target groups and targeted health behaviors, but that gamification is also context-sensitive with regard to different stages of the health behavior change process. Practitioners need to bear in mind these different levels of context-sensitivity when designing gamification. Analyzing targeted behaviors confirmed the observations of other studies [47] that physical activity is the dominant health behavior targeted in published research on gamified interventions. While results of this application context are unlikely to be easily transferable to other contexts, this finding reveals the need for more theory-driven research on the role of gamification in health behavior change contexts such as smoking cessation or medication adherence. Finally, by deriving concrete research questions with respect to different theoretical lenses, we provide future researchers with explicit valuable starting points to further investigate the role of gamification in the health behavior change process.

\subsection{Limitations}

Our research is limited by a number of factors. First, we limited our review on such HBCTs that have been widely used by the healthcare research community as proposed by Munro et al. [37]. Thus, other theories that are not as closely related to the health context but frequently used in gamification research (e.g., SDT) were not considered within this review. Another aspect to consider is the fact that the study Munro et al. focused on HBCTs for the specific behavior of medication adherence and as such might not provide a comprehensive list of HBCTs for other contexts. However, most HBCTs are largely behavior independent, and even those that have been developed with a specific behavior in mind (e.g. the TTM for smoking cessation) have since been utilized or tested in a broad range of contexts. Thus, we think that the list by Munro et al. provides us with a suitable base for our review. Furthermore, our coding was dependent on explicit mentions of the HBCTs. Thus, we cannot rule out that authors implicitly drew knowledge from certain HBCTs without explicitly stating this in the manuscript. Additionally, a limitation is the use of keywords related to behavior in our literature search. As a large part of the gamification research in healthcare is somehow related to behavior change, but does not necessarily mention the word, the reach of our literature review is limited. However, we aimed to offset this limitation to some degree by conducting a forward and a backward search.

\section{Conclusion}

The goal of this research was to investigate the role of gamification in health behavior change. We approached to answer this question by reviewing 25 studies that draw on HBCTs and gamification to explain health behavior change. Our results reveal large discrepancies in the way that researchers have conceptualized the role of gamification in HBCT-driven health interventions. While some HBCTs have been given greater considerations by researchers in the past (e.g., TTM), others remain largely understudied (e.g., IMB). In order to contribute to filling this gap, we derived concrete research questions with regard to different HBCTs. It is upon future research to build on our findings and conduct more theory-driven research that helps to understand and predict how gamification may contribute to positive health behavior change. 


\section{References}

[1] Ahola, R., Pyky, R., Jämsä, T., Mäntysaari, M., Koskimäki, H., ... , and Korpelainen, R., "Gamified physical activation of young men - a Multidisciplinary PopulationBased Randomized Controlled Trial (MOPO study)", BMC public health, 13(1), 2013, pp. 1-8.

[2] Ajzen, I., "The theory of planned behavior", Organizational Behavior and Human Decision Processes, 50(2), 1991, pp. 179-211.

[3] Bandura, A., and Walters, R. H., Social learning theory, Prentice-hall Englewood Cliffs, NJ, 1977.

[4] Benyamini, Y., Gozlan, M., and Kokia, E., "On the selfregulation of a health threat: Cognitions, coping, and emotions among women undergoing treatment for infertility", Cognitive Therapy and Research, 28(5), 2004, pp. 577-592. [5] Cugelman, B., "Gamification: what it is and why it matters to digital health behavior change developers", JMIR Serious Games, 1(1), 2013, e3.

[6] Dadaczynski, K., Schiemann, S., and Backhaus, O. "Promoting physical activity in worksite settings: results of a German pilot study of the online intervention Healingo fit", BMC public health, 17(1), 2017, pp. 1-9.

[7] Deterding, S., Dixon, D., Khaled, R., and Nacke, L., "From game design elements to gamefulness", in Proceedings of the 15th International Academic MindTrek Conference on Envisioning Future Media Environments, Finland. 2011. [8] Edney, S., Plotnikoff, R., Vandelanotte, C., Olds, T., Bourdeaudhuij, I. de, ..., and Maher, C., "'Active Team" a social and gamified app-based physical activity intervention: randomised controlled trial study protocol", BMC public health, 17, 2017, pp. 1-10.

[9] Edwards, E.A., Caton, H., Lumsden, J., Rivas, C., Steed, L., ..., and Walton, R. T., "Creating a Theoretically Grounded, Gamified Health App: Lessons From Developing the Cigbreak Smoking Cessation Mobile Phone Game", JMIR Serious Games, 6(4), 2018, e10252.

[10] El-Hilly, A.A., Iqbal, S.S., Ahmed, M., Sherwani, Y., Muntasir, M., ... , and Eisingerich, A. B., "Game On? Smoking Cessation Through the Gamification of mHealth: A Longitudinal Qualitative Study", JMIR Serious Games, 4(2), 2016, e18.

[11] Festinger, L., "A theory of social comparison processes", Human relations, 7(2), 1954, pp. 117-140.

[12] Fisher, J.D., Fisher, W.A., Amico, K.R., and Harman, J. J., "An information-motivation-behavioral skills model of adherence to antiretroviral therapy", Health psychology, 25(4), 2006, pp. 462-473.

[13] Giunti, G., "3MD for chronic conditions, a model for motivational mHealth design: Embedded case study", Journal of medical Internet research, 6(3), 2018, e11631.

[14] Giunti, G., Mylonopoulou, V., and Rivera Romero, O., "More Stamina, a Gamified mHealth Solution for Persons with Multiple Sclerosis: Research Through Design", JMIR mHealth and uHealth, 6(3), 2018, e51.

[15] Gochman, D.S., "Labels, Systems and Motives: Some Perspectives For Future Research and Programs", Health

Education Quarterly, 9(2-3), 1982, pp. 167-174.
[16] Hamari, J., and Koivisto, J., "“Working out for likes": An empirical study on social influence in exercise gamification", Computers in Human Behavior, 50, 2015, pp. 333-347.

[17] Hamari, J., Koivisto, J., and Sarsa, H., "Does

Gamification Work?-A Literature Review of Empirical Studies on Gamification", in 47th Hawaii International Conference on System Sciences, Waikoloa, HI. 2014.

[18] Helf, C., and Hlavacs, H., "Apps for life change: Critical review and solution directions", Entertainment Computing, 14, 2016, pp. 17-22.

[19] Hightow-Weidman, L., Muessig, K., Knudtson, K., Srivatsa, M., Lawrence, E., ... , and Hosek, S., "A Gamified Smartphone App to Support Engagement in Care and Medication Adherence for HIV-Positive Young Men Who Have Sex With Men (AllyQuest): Development and Pilot Study", JMIR public health and surveillance, 4(2), 2018, e34. [20] Huotari, K., and Hamari, J., "Defining gamification", in Proceeding of the 16th International Academic MindTrek Conference, Proceeding of the 16th International Academic MindTrek Conference, Tampere, Finland. 2012.

[21] Johnson, D., Deterding, S., Kuhn, K.-A., Staneva, A., Stoyanov, S., ..., and Hides, L., "Gamification for health and wellbeing: A systematic review of the literature", Internet Interventions, 6, 2016, pp. 89-106.

[22] Jones, B.A., Madden, G.J., Wengreen, H.J., Aguilar, S.S., and Desjardins, E. A., "Gamification of dietary decision-making in an elementary-school cafeteria", PLoS ONE, 9(4), 2014, e93872.

[23] Kamel Boulos, M.N., Gammon, S., Dixon, M.C., MacRury, S.M., Fergusson, M.J., ... , and Yang, S. P., "Digital games for type 1 and type 2 diabetes: underpinning theory with three illustrative examples", JMIR Serious Games, 3(1), 2015, e3.

[24] Kamel Boulos, M.N., and Yang, S. P., "Exergames for health and fitness: The roles of GPS and geosocial apps", International Journal of Health Geographics, 12(18), 2013. [25] Koivisto, J., and Hamari, J., "Demographic differences in perceived benefits from gamification", Computers in Human Behavior, 35, 2014, pp. 179-188.

[26] Koivisto, J., and Hamari, J., "The rise of motivational information systems: A review of gamification research", International Journal of Information Management, 45, 2019, pp. 191-210.

[27] Krasnova, H., Widjaja, T., Buxmann, P., Wenninger, H., and Benbasat, I., "Research note- - why following friends can hurt you: an exploratory investigation of the effects of envy on social networking sites among college-age users", Information systems research, 26(3), 2015, pp. 585-605. [28] LeGrand, S., Muessig, K.E., Platt, A., Soni, K., Egger, J.R., ..., and Hightow-Weidman, L. B., "Epic allies, a gamified mobile phone app to improve engagement in care, antiretroviral uptake, and adherence among young men who have sex with men and young transgender women who have sex with men: Protocol for a randomized controlled trial", JMIR research protocols, 7(4), 2018, e94.

[29] Leinonen, A.-M., Pyky, R., Ahola, R., Kangas, M., Siirtola, P., ..., and Jamsa, T., "Feasibility of Gamified Mobile Service Aimed at Physical Activation in Young Men: 
Population-Based Randomized Controlled Study (MOPO)", JMU, 5(10), 2017, e146.

[30] Leventhal, H., Meyer, D., and Nerenz, D., "The common sense representation of illness danger", Contributions to medical psychology, 2, 1980, pp. 7-30.

[31] Levy, Y., and Ellis, T. J., "A systems approach to conduct an effective literature review in support of information systems research", Informing Science, 9, 2006, pp. 181-212.

[32] Lin, R.J., Ramakrishnan, S., Chang, H., Spraragen, S., and Zhu, X., "Designing a web-based behavior motivation tool for healthcare compliance", Human Factors and Ergonomics In Manufacturing, 23(1), 2013, pp. 58-67. [33] Lister, C., West, J.H., Cannon, B., Sax, T., and Brodegard, D., "Just a Fad? Gamification in Health and Fitness Apps", JMIR Serious Games, 2(2), 2014, e9. [34] Liu, D., Santhanam, R., and Webster, J., "Toward Meaningful Engagement: A Framework for Design and Research of Gamified Information Systems", MIS Quarterly, 41(4), 2017, pp. 1011-1034.

[35] Martin, G., and Pear, J. J., Behavior Modification: What it is and how to do it., 10th edn., Psychology Press, New York, 2015.

[36] Michie, S., Johnston, M., Abraham, C., Lawton, R., Parker, D., ..., and Walker, A., "Making psychological theory useful for implementing evidence based practice: a consensus approach", Quality \& safety in health care, 14(1), 2005, pp. 26-33.

[37] Munro, S., Lewin, S., Swart, T., and Volmink, J., "A review of health behaviour theories: how useful are these for developing interventions to promote long-term medication adherence for TB and HIV/AIDS?", BMC public health, 7, 2007, p. 104.

[38] Nacke, L.E., and Deterding, S., "The maturing of gamification research", Computers in Human Behavior, 71, 2017, pp. 450-454.

[39] Prochaska, J.O., and Velicer, W. F., "The

transtheoretical model of health behavior change", American journal of health promotion, 12(1), 1997, pp. 38-48.

[40] Putz, L.-M., and Treiblmaier, H., "Creating a theorybased research agenda for gamification", in Proceedings of the 20th Americas Conference on Information Systems. 2015: Savannah.

[41] Pyky, R., Koivumaa-Honkanen, H., Leinonen, A.-M., Ahola, R., Hirvonen, N., ... , and Korpelainen, R., "Effect of tailored, gamified, mobile physical activity intervention on life satisfaction and self-rated health in young adolescent men: A population-based, randomized controlled trial (MOPO study)", Computers in Human Behavior, 72, 2017, pp. 13-22.

[42] Reynolds, L., Sosik, V.S., and Cosley, D., "When Wii doesn't fit: How non-beginners react to Wii Fit's gamification", in Proceedings of the 1st International Conference on Gameful Design, Research, and Applications, Ontario, Canada. 2013.

[43] Ryan, R.M., and Deci, E. L., "Self-determination theory and the facilitation of intrinsic motivation, social development, and well-being", American Psychologist, 55(1), 2000, pp. 68-78.
[44] Sardi, L., Idri, A., and Fernández-Alemán, J. L., "A systematic review of gamification in e-Health", Journal of biomedical informatics, 71, 2017, pp. 31-48.

[45] Schmidt-Kraepelin, M., Thiebes, S., Baumsteiger, D., and Sunyaev, A., "State of Play: A Citation Network Analysis of Healthcare Gamification Studies", in 26th European Conference on Information Systems, Portsmouth, UK. 2018.

[46] Schmidt-Kraepelin, M., Thiebes, S., Stepanovic, S., Mettler, T., and Sunyaev, A., "Gamification in health behavior change support systems-A synthesis of unintended side effects", in Proceedings of the 14th International Conference on Wirtschaftsinformatik, Germany. 2019. [47] Schmidt-Kraepelin, M., Thiebes, S., Tran, M.C., and Sunyaev, A., "What's in the Game? Developing a Taxonomy of Gamification Concepts for Health Apps", in Proceedings of the 51st Hawaii International Conference on System Sciences (HICSS), Waikoloa, HI. 2018.

[48] Schoech, D., Boyas, J.F., Black, B.M., and EliasLambert, N., "Gamification for Behavior Change: Lessons from Developing a Social, Multiuser, Web-Tablet Based Prevention Game for Youths", Journal of Technology in Human Services, 31(3), 2013, pp. 197-217.

[49] Seaborn, K., and Fels, D. I., "Gamification in theory and action: A survey", International Journal of Human-Computer Studies, 74, 2015, pp. 14-31.

[50] Skinner, C.S., Tiro, J., and Champion, V. L.,

"Background on the health belief model", in Health Behavior: Theory, Research, and Practice.

[51] Stepanovic, S., and Mettler, T., "Gamification applied for health promotion: does it really foster long-term engagement? A scoping review", in Proceedings of the 26th European Conference on Information Systems. 2018: Portsmouth, UK.

[52] Takahashi, M., Kawasaki, H., Maeda, A., and Nakamura, M., "Mobile walking game and group-walking program to enhance going out for older adults", in Proceedings of the 2016 ACM International Joint Conference on Pervasive and Ubiquitous Computing, Heidelberg, Germany. 2016.

[53] Thiebes, S., Lins, S., and Basten, D., "Gamifying information systems-a synthesis of gamification mechanics and dynamics", in Proceedings of the 22nd European Conference on Information Systems. 2014: Tel Aviv, Israel. [54] Vette, F. de, Tabak, M., Dekker-van Weering, M., and Vollenbroek-Hutten, M., "Engaging Elderly People in Telemedicine Through Gamification", JMIR Serious Games, 3(2), 2015, e9.

[55] Webster, J., and Watson, R. T., "Analyzing the past to prepare for the future: Writing a literature review", MIS Quarterly, 26(2), 2002, pp. 13-23.

[56] White, B.K., Martin, A., White, J.A., Burns, S.K., Maycock, B.R., ..., and Scott, J. A., "Theory-Based Design and Development of a Socially Connected, Gamified Mobile App for Men About Breastfeeding (Milk Man)", JMU, 4(2), 2016, e81. 


\section{Appendix}

Appendix A: Studies included in literature review

\begin{tabular}{|c|c|c|c|c|c|c|c|c|}
\hline ID & Main focus of study & HBCT & Int.* & $\begin{array}{l}\text { Type of } \\
\text { Study }\end{array}$ & $\begin{array}{l}\text { Methods used } \\
\text { in study }\end{array}$ & $\mathbf{N}$ & $\begin{array}{l}\text { Targeted } \\
\text { Behavior }\end{array}$ & $\begin{array}{l}\text { Target } \\
\text { group }\end{array}$ \\
\hline$[1]$ & $\begin{array}{l}\text { Study protocol for gamified } \\
\text { intervention }\end{array}$ & TTM & $\mathrm{P}$ & quantitative & $\begin{array}{l}\text { Questionnaires, RCT, } \\
\text { Study protocol }\end{array}$ & 1500 & Physical activity & $\begin{array}{l}\text { Young } \\
\text { men }\end{array}$ \\
\hline$[5]$ & $\begin{array}{l}\text { Discuss gamification in behavior } \\
\text { change systems }\end{array}$ & SRT & M & conceptual & Discussion & $\mathrm{n} / \mathrm{a}$ & $\mathrm{n} / \mathrm{a}$ & $\mathrm{n} / \mathrm{a}$ \\
\hline$[6]$ & $\begin{array}{l}\text { Pilot study to evaluate efficacy of } \\
\text { own gamified intervention }\end{array}$ & $\begin{array}{l}\text { SCT } \\
\text { TPB }\end{array}$ & $\begin{array}{l}\mathrm{P} \\
\mathrm{P}\end{array}$ & quantitative & RCT, Statistical analysis & 144 & Physical activity & Adults \\
\hline$[8]$ & $\begin{array}{l}\text { Study protocol for gamified } \\
\text { intervention }\end{array}$ & SCT & $\mathrm{F}$ & quantitative & RCT & 440 & Physical activity & Adults \\
\hline$[9]$ & $\begin{array}{l}\text { Develop a theoretically grounded } \\
\text { gamified intervention }\end{array}$ & SCT & $M$ & qualitative & Focus groups & 73 & Smoking cessation & Smokers \\
\hline$[10]$ & $\begin{array}{l}\text { Investigate effects of gamification on } \\
\text { mHealth interventions }\end{array}$ & HBM & $S$ & qualitative & $\begin{array}{l}\text { Qualitative longitudinal } \\
\text { study, interviews }\end{array}$ & 16 & Smoking cessation & Smokers \\
\hline$[13]$ & $\begin{array}{l}\text { Discover factors for design of } \\
\text { mHealth solutions, develop own } \\
\text { model }\end{array}$ & $\begin{array}{l}\text { HBM } \\
\text { SRT } \\
\text { TPB }\end{array}$ & $\begin{array}{l}\mathrm{P} \\
\mathrm{M} \\
\mathrm{P}\end{array}$ & $\begin{array}{l}\text { mixed } \\
\text { methods }\end{array}$ & $\begin{array}{l}\text { App review, focus } \\
\text { groups, interviews, } \\
\text { surveys }\end{array}$ & $\begin{array}{l}600 \\
\text { apps }\end{array}$ & $\begin{array}{l}\text { Chronic condition } \\
\text { self-management }\end{array}$ & $\begin{array}{l}\text { Chronic } \\
\text { disease } \\
\text { patients }\end{array}$ \\
\hline$[14]$ & $\begin{array}{l}\text { Design \& evaluation of a gamified } \\
\text { mHealth solution }\end{array}$ & $\begin{array}{l}\text { HBM } \\
\text { TPB }\end{array}$ & $\begin{array}{l}\mathrm{P} \\
\mathrm{P}\end{array}$ & conceptual & Prototyping & $\mathrm{n} / \mathrm{a}$ & Physical Activity & $\begin{array}{l}\text { Multiple } \\
\text { Sclerosis } \\
\text { patients }\end{array}$ \\
\hline \begin{tabular}{|l|}
{$[16]$} \\
\end{tabular} & $\begin{array}{l}\text { Investigate social influence in } \\
\text { gamified interventions }\end{array}$ & TPB & $\mathrm{P}$ & quantitative & Online Questionnaires & 200 & Physical Activity & $\mathrm{n} / \mathrm{a}$ \\
\hline$[18]$ & $\begin{array}{l}\text { Critical review of the health app } \\
\text { landscape }\end{array}$ & $\begin{array}{l}\text { HBM } \\
\text { TTM }\end{array}$ & $\begin{array}{l}\mathrm{M} \\
\mathrm{M}\end{array}$ & conceptual & App review & $\mathrm{n} / \mathrm{a}$ & $\mathrm{n} / \mathrm{a}$ & $\mathrm{n} / \mathrm{a}$ \\
\hline \begin{tabular}{|l|}
{$[19]$} \\
\end{tabular} & Development of own intervention & SCT & $\mathrm{P}$ & $\begin{array}{l}\text { Mixed } \\
\text { methods }\end{array}$ & $\begin{array}{l}\text { Pilot Trial, statistical } \\
\text { analysis, Interviews }\end{array}$ & 20 & $\begin{array}{l}\text { Engagement in } \\
\text { HIV Care }\end{array}$ & $\begin{array}{l}\text { HIV } \\
\text { patients }\end{array}$ \\
\hline$[21]$ & $\begin{array}{l}\text { Assess advantages of gamification } \\
\text { applied to health }\end{array}$ & TTM & $M$ & conceptual & Literature review & 19 & $\mathrm{n} / \mathrm{a}$ & $\mathrm{n} / \mathrm{a}$ \\
\hline$[22]$ & $\begin{array}{l}\text { Investigate effects of own gamified } \\
\text { intervention }\end{array}$ & SCT & $\mathrm{F}$ & quantitative & $\begin{array}{l}\text { Measuring of food waste, } \\
\text { Post-surveys }\end{array}$ & 180 & \begin{tabular}{|l} 
Fruit and \\
vegetable \\
consumption
\end{tabular} & \begin{tabular}{|l} 
Students, \\
$5-14$ yrs \\
old
\end{tabular} \\
\hline$[23]$ & $\begin{array}{l}\text { Present examples of digital games for } \\
\text { diabetes patients }\end{array}$ & \begin{tabular}{|l} 
SCT, \\
TTM
\end{tabular} & $\begin{array}{l}\mathrm{P} \\
\mathrm{P}\end{array}$ & conceptual & Discussion & $\mathrm{n} / \mathrm{a}$ & $\begin{array}{l}\text { Diabetes Self- } \\
\text { Management }\end{array}$ & $\begin{array}{l}\text { Diabetes } \\
\text { patients }\end{array}$ \\
\hline$[24]$ & $\begin{array}{l}\text { Review GPS exergames and discuss } \\
\text { issues }\end{array}$ & SCT & $M$ & conceptual & Discussion & $\mathrm{n} / \mathrm{a}$ & Physical Activity & $\begin{array}{l}\text { Adolescen } \\
\text { ts }\end{array}$ \\
\hline$[28]$ & $\begin{array}{l}\text { Investigate effects of own gamified } \\
\text { intervention }\end{array}$ & IBM & $\mathrm{F}$ & quantitative & RCT & 146 & $\begin{array}{l}\text { Engagement in } \\
\text { HIV Care }\end{array}$ & $\begin{array}{l}\text { HIV risk } \\
\text { groups }\end{array}$ \\
\hline \begin{tabular}{|l|}
{$[29]$} \\
\end{tabular} & $\begin{array}{l}\text { Investigate feasibility of own } \\
\text { gamified intervention }\end{array}$ & TTM & $\mathrm{F}$ & quantitative & RCT, statistical analysis & 496 & Physical activity & $\begin{array}{l}\text { Young } \\
\text { men }\end{array}$ \\
\hline$[32]$ & $\begin{array}{l}\text { Proposition of web-based behavior } \\
\text { motivation tool }\end{array}$ & SCT & $\mathrm{P}$ & conceptual & Development guidelines & $\mathrm{n} / \mathrm{a}$ & $\begin{array}{l}\text { Health } \\
\text { Compliance }\end{array}$ & $n / a$ \\
\hline$[33]$ & $\begin{array}{l}\text { Identify and analyze extent of } \\
\text { gamification usage in health apps }\end{array}$ & $\begin{array}{l}\text { HBM } \\
\text { SCT } \\
\text { TPB } \\
\text { TTM }\end{array}$ & $\begin{array}{l}\mathrm{S} \\
\mathrm{S} \\
\mathrm{S} \\
\mathrm{S}\end{array}$ & conceptual & $\begin{array}{l}\text { App review, statistical } \\
\text { analysis }\end{array}$ & $\begin{array}{l}132 \\
\text { apps }\end{array}$ & $\begin{array}{l}\text { Physical activity } \\
\& \text { diet }\end{array}$ & $\mathrm{n} / \mathrm{a}$ \\
\hline$[41]$ & $\begin{array}{l}\text { Investigate effects of own gamified } \\
\text { intervention }\end{array}$ & TTM & $\mathrm{F}$ & quantitative & RCT, statistical analysis & 496 & Physical activity & $\begin{array}{l}\text { Adolescen } \\
\text { ts }\end{array}$ \\
\hline \begin{tabular}{|l|l}
{$[42]$} \\
\end{tabular} & $\begin{array}{l}\text { Beginners vs non-beginners in } \\
\text { persuasive health technologies }\end{array}$ & TTM & S & qualitative & $\begin{array}{l}\text { Interviews, observation } \\
\text { sessions }\end{array}$ & 15 & \begin{tabular}{|l|} 
Weight-loss / \\
Fitness
\end{tabular} & Adults \\
\hline$[48]$ & $\begin{array}{l}\text { Lessons from developing gamified } \\
\text { intervention }\end{array}$ & \begin{tabular}{|l|} 
SCT \\
TPB \\
TTM
\end{tabular} & $\begin{array}{l}\mathrm{M} \\
\mathrm{M} \\
\mathrm{M}\end{array}$ & conceptual & $\begin{array}{l}\text { Description \& test of } \\
\text { gamified intervention }\end{array}$ & $\mathrm{n} / \mathrm{a}$ & $\begin{array}{l}\text { Substance Abuse } \\
\text { and Relationship } \\
\text { Violence }\end{array}$ & Youths \\
\hline $\mid[52]$ & $\begin{array}{l}\text { Develop an own gamified } \\
\text { intervention }\end{array}$ & HBM & $S$ & quantitative & $\begin{array}{l}\text { User study, } \\
\text { questionnaires }\end{array}$ & 30 & Physical activity & Elderly \\
\hline \begin{tabular}{|l|}
{$[54]$} \\
\end{tabular} & $\begin{array}{l}\text { Provide overview of theoretical } \\
\text { frameworks for gamification }\end{array}$ & TTM & $M$ & conceptual & Broad internet search & $\mathrm{n} / \mathrm{a}$ & $\mathrm{n} / \mathrm{a}$ & Elderly \\
\hline \begin{tabular}{|l|}
{$[56]$} \\
\end{tabular} & $\begin{array}{l}\text { Develop evidence-based gamified } \\
\text { intervention }\end{array}$ & SCT & $\mathrm{F}$ & qualitative & $\begin{array}{l}\text { App development, focus } \\
\text { groups, think-aloud study }\end{array}$ & 38 & $\begin{array}{l}\text { Support for } \\
\text { Breastfeeding }\end{array}$ & Fathers \\
\hline
\end{tabular}

*Level of theory integration: M: Mention, S: Subsumption, P: Partial Basis, F: Full Basis 